\title{
Introducing the Data descriptor article
}

CrossMark

\author{
Charles H. Ward
}

Correspondence:

charles.ward.4@us.af.mil

Air Force Research Laboratory,

Dayton, $\mathrm{OH}$ 45433, USA
Earlier this year, we announced the launch of a new type of scholarly publication for Integrating Materials and Manufacturing Innovation (IMMI): the Data descriptor article. By introducing the Data descriptor article, we are responding to the growing dependence of research on having access to high-quality materials data. The Data descriptor article aims to provide researchers with the necessary supporting information, or metadata, needed to fully understand and use the data described with a high degree of confidence.

A number of compelling needs underpin this new, peer-reviewed forum for the presentation of high-quality, high-value materials data. Most would agree that materials data can be extraordinarily rich in information, but we typically only use a subset of the data collected to explore a fairly focused hypothesis. Thus, it makes good sense, as research budgets are always constrained, to provide a forum to facilitate the reuse of materials data for a more efficient research process. Others can use available data to augment or corroborate their own research, perhaps testing a secondary hypothesis not even considered by the data originator. And as we become more dependent on models of materials behavior to guide advances in science or support engineering design, we have a growing need to develop, refine, and validate these models. Ready access to high-quality data will aid theoreticians and modelers in these pursuits. With the emergence of data analytic techniques, we also have the opportunity to gain new insights into material behavior from complex datasets where we do not yet have robust physics-based models of behavior. And finally, it is just sound scientific practice, and the core of the peer-review process, to allow others to examine the data upon which new scientific claims are based.

There are several key elements to the Data descriptor article that are aimed at ensuring the data described is at least as valuable to others as it was to the originator. First and foremost is a requirement for a significantly more detailed description of the materials and experimental and/or simulation techniques and conditions used to generate the data than found in a typical research article. Also, we are asking authors to specifically address attributes of data quality, to appropriate levels, including steps taken in verification, validation, uncertainty quantification, and sensitivity to assumptions and variables. We are requiring the data be made available for peer review prior to publication to ensure the data is interpretable by someone else other than the originator. Finally, we are requiring that the data described be made accessible to all without restriction and that the data be assigned a persistent identifier to ensure it can be more easily discovered and properly cited. 
IMMI's first Data descriptor article, by M. Tschopp, S.P. Coleman, and D.L. McDowell, describes the data resulting from a Large-scale Atomic/Molecular Massively Parallel Simulator (LAMMPS) simulation of 348 symmetric and asymmetric tilt grain boundaries in $\mathrm{Al}$ and $\mathrm{Cu}$. Each grain boundary is described at its minimum energy state and contains the atomic coordinates in three-dimensional periodic simulation cells. The data described will be valuable to others studying a variety of phenomena including nanomechanical, thermodynamic, and kinetic processes such as dislocation nucleation and interaction with grain boundaries and grain boundary mobility and diffusion. The article is an excellent example of a rich and high-quality dataset that many others in the field will find useful in the conduct of their own research.

Received: 17 September 2015 Accepted: 20 September 2015

Published online: 28 October 2015

Submit your manuscript to a SpringerOpen ${ }^{\odot}$ journal and benefit from:

- Convenient online submission

- Rigorous peer review

- Immediate publication on acceptance

- Open access: articles freely available online

- High visibility within the field

- Retaining the copyright to your article

Submit your next manuscript at $>$ springeropen.com 